\title{
Fraud in the Russian labor market: a systematic review
}

\author{
Anna Vergazova ${ }^{1}$ \\ Financial University under the Government of the Russian Federation, Department of Sociology and \\ Mass Communications, Moscow, Russia
}

\begin{abstract}
This article synthesizes the current knowledge available on the fraud practices in the Russian labor market by conducting a systematic literature review among various databases. The focus of this review is to categorize and conceptualize the diversified types of fraud in the labor market and understand the challenges such practices present. The study is based entirely on the available secondary data collected from Russian and non-Russian academic databases for the last 5 years (2017-2021) in line with the guidelines into best practice. The aim is to promote social security by combining the state-of-the-art body of knowledge of the Russian labor market with respect to all its agents in terms of deviant sociology measures. The findings of this review show current gaps both in academic and legislative practices for approaching fraud in the labor market and present the challenges to overcome for avoiding further negative effects on the economy and society.
\end{abstract}

Keywords: fraud, labor market, deviant behaviour, systematic literature review, workers' rights

\section{Introduction}

The current state of the global economy, part of which the labor market is, could be characterized as unstable. This is also applicable for the Russian market, which due to the pandemic, foreign sanctions, fluctuations of the ruble, and other factors is in a high state of vulnerability.

According to the recent studies [1] conducted by the Ministry of Labor of the Russian Federation, the forecast for the Russian labor market before the global pandemic included the following trends: (i) decline of unemployment (ii); rise of the working-age population (iii); decline of the employed population (iv), increase in migrant workers. The pandemic has changed the dynamics by heavily affecting various sectors of the economy, as well as by the fact that the Russian Federation has closed its borders to migration for preventing the rise of infection rates.

With the increasing dynamics of social processes, there is also a parallel trend, namely, the rise of deviant behavior practices in society, both negative and positive. In that sense, citizens become less safe in their own state as there is no protection from the emerging

\footnotetext{
${ }^{1}$ Corresponding author: atvergazova@fa.ru
} 
deviant practices on the corporate and individual levels. Therefore, the need for accumulating knowledge of what those behaviors are, how they are practiced, what are their social effects and how the damage can be prevented is rising [2].

Moreover, the market is also affected by modern processes. With the rise of digitalization, development of the digital economy [3] and new forms of employment [4], the market and social policies are yet to adapt to the new reality and form mechanisms for protecting its agents.

Having said the above, the labor market is threatened by deviant behaviors, one of which is fraud. This study defines fraud according to Article 159 of the Criminal Code of the Russian Federation (theft of another's property or acquisition of the right to another's property by deception or abuse of trust) [5]. Fraud could be conducted by all the agents of the labor market - employers, employees, job-seekers, or job agencies. This review focuses on fraud that has workers as victims.

Literature suggests that the reason fraud occurs is not the complete absence of law, but politics that are more protective of stakeholders rather than workers along with the fact there are not so many possibilities for workers to protect themselves. The reason for that is mainly the absence of such knowledge [6].

This makes studying fraud as deviant behavior in the labor market a vital concern due to its evolving and rising character. Therefore, the study seeks to (i) categorize fraud in the Russian labor market; (ii) highlight current challenges; (iii) outline potential negative effects of practicing such behaviors. This is going to be achieved via a systematic literature review.

\section{$2 \quad$ Materials and methods}

A systematic review of the literature was conducted by adapting the Preferred Reporting Items for Systematic Reviews and Meta-Analysis (PRISMA) protocol [7]. The review included academic literature in Russian and English that was focused on fraud in the Russian labor market.

Using various databases ensures that the study achieves the objective of collecting the entire available body of knowledge. The string used for the search was "fraud labor market" (in Russ.). For the search in English, the word "Russia" was also included in the string. Between all the words, the "AND" operator was used to ensure all of the key terms for this study were included in the text of the articles and for excluding articles non-related to the topic in focus. The search was also limited by articles published in the timeframe between 2017 and 2021.

A total of 108 articles were included in the final corpus of analysis. Table 1 displays the identification and selection protocol.

Table 1. Identification and selection protocol

\begin{tabular}{|l|c|c|c|c|c|c|c|}
\hline Database & Total & $\begin{array}{c}\text { Taken } \\
\text { into } \\
\text { analysi } \\
\text { s }\end{array}$ & $\mathbf{2 0 1 7}$ & $\mathbf{2 0 1 8}$ & $\mathbf{2 0 1 9}$ & $\mathbf{2 0 2 0}$ & $\mathbf{2 0 2 1}$ \\
\hline eLibrary & 12 & 7 & 0 & 3 & 2 & 2 & 0 \\
\hline EBSCO & 6 & 1 & 0 & 0 & 1 & 0 & 0 \\
\hline JSTOR & 20 & 1 & 0 & 0 & 0 & 0 & 1 \\
\hline ScienceDirect & 68 & 0 & 0 & 0 & 0 & 0 & 0 \\
\hline Scopus & 2 & 0 & 0 & 0 & 0 & 0 & 0 \\
\hline
\end{tabular}




\begin{tabular}{|l|c|c|c|c|c|c|c|}
\hline Web of Science & 0 & 0 & 0 & 0 & 0 & 0 & 0 \\
\hline $\begin{array}{l}\text { Academic } \\
\text { Reference }\end{array}$ & 0 & 0 & 0 & 0 & 0 & 0 & 0 \\
\hline
\end{tabular}

\section{$3 \quad$ Results}

Types of deviant behaviors. Deviant behaviors in the Russian labor market started developing in the 1990s but yet they have not been established as a subject of study in the academic literature [8]. Therefore, fraud mainly comes from the fact that usually the relationship between the employer and the employee is developing based mostly on the word of trust with no back-up documentation that ensures the rights of each agent. Kiryukhina et al. [9] identify the following types of deviant behavior in the labor market from the side of the employers or employing agents (fraud being highlighted):

- Empty vacancies - available job announcements that are not monitored anymore by the employer, meaning that the applicants never receive any feedback;

- Theft of the employee's funds - the most common way to do so happens by assuring the employee they are a good fit for the placement but asking to pay for some educational or other materials as the last step of the selection process. As a result, the employer gets either directly the money or the employee's credit card information;

- Personal data theft - as a result, the employee becomes a potential victim of spam, fishing, or financial fraud;

- Using potential employees as free labor - the employer asks the potential candidates to perform a task and after receiving the results stops any further communication;

- Recruiting the employee in a pyramid or other scheme - the employee is asked to invest a certain amount of money for becoming part of some pyramided scheme or another scheme that is supposed to lead to profit from the invested money which in reality never takes place;

- Asking the candidate to pay for a vacancies database - such behaviors usually are implemented by agencies that promise to send the candidate a database of vacancies that fit their profile. The outcome could be either theft of money when the applicant pays for a service but does not receive any further communication, or when the applicant receives a database that includes vacancies available in open-sourced resources.

Other types of deviant behavior may be related to schemes for not paying salary to the worker by not following the law or completely dismissing workers' rights. As a result, when an investigation is initiated the worker has to prove the fact a relationship with the employer existed and fraud actions indeed took place. Moreover, types of fraud in the labor market become more and more complicated, which makes it harder to catch such behavior and put it under investigation properly [10].

Effects of deviant behaviors. Apart from regular employment types, workers may also belong to the category of the precariat. Being included in such a category could be either voluntarily or for reasons beyond control. The precariat consists of: (i) temporary workers; (ii) part-time workers with seasonal or occasional payments; (iii) unemployed; (iv) freelancers; (v) trainees and students. Some authors include in that group also employees of borrowed labor (against the law since 2016) and migrants.

The precariat does not enjoy the social policies applicable for contracted workers which makes them more vulnerable to acts of fraud. Moreover, the group is growing as the reasons for becoming part of it are the same as the reasons for unemployment. Dudina and Golovanova [11] suggest that in the future, precarization would grow in size. Currently, this 
group does not have internal instruments for aid, neither their relationship with the employers is regulated to a full extend. It is expected that if this factor does not change, fraud in that group will rise as its size grows.

Academic literature mentions the vulnerable state of the precariat, namely the migrants that have to navigate the labor market being forced to operate by the rules of the shadow economy [12]. Such informal employment is estimated to constitute between one-fifth and one-third of all employment. Given this number, it is highly unlikely that there are ways to measure it precisely, as well as to assess its current and future effects. Authors mention among the reasons why this is happening the complicated legislative process to legalize such typed of employments, especially among migrants to Russia.

The effects for the employees that have been subject to fraud are the following: (i) loss of money may put the household financially to a critical level which can also ruin family life; (ii) time that could be used productively in the economy is wasted on dealing with fraud; (iii) the person's ability to work decreases, while mental illnesses such as depression, irritability, and psychopathic disorders may appear; (iv) the trust in the labor market is undermined, which complicates further job search [13].

Some authors also state that due to the extensive Internet coverage, entering the labor market is easier than ever before. However, some employers choose to hire workers using traditional methods [14] for avoiding complexities. Apart from that, some employers choose not to invest enough for having a comprehensive system for their job placements online which also makes them more vulnerable to fraud [15].

As stated above, there is a risk that the financial situation of the victims of fraud could worsen, and their trust in the labor market will decrease. This affects the economy, while workers are left alone to deal with their problems and there is a chance that they will remain either unemployed or become less economically active.

\section{Discussion}

Protection from fraud remains now mainly a problem solved by its own victims. Russian workers have to take measures themsleves to ensure they do not become a subject of fraud and there is little the state or the employer can do to ensure their safety, especially if the workers belong to certain more vulnerable categories such as the precariat [11].

However, certain measures were suggested in the literature such as involving the police to a bigger extend in the investigation of fraud cases [13] and working on awareness in the digital environment [15]. Apart from that, some authors state that one of the reasons for fraud in the labor market is that workers are not familiar with the law and their own rights [8].

The legislation system in Russia that has yet to adapt to the new realities is posing challenges for the market that has developed its own shadow part with a parallel order [12]. Informal employment becomes a space that is not institutionalized and, therefore, all types of deviant behaviors could be easily adopted there.

As not much knowledge is accumulated on what exactly fraud is in the all-Russia labor market, the authors tend to develop ideas that are coming close to each other yet do not provide a full picture of how it can be eliminated and fought. Having said that, there is no current assessment of how big the actual level of fraud is neither how much it does affect the society and behaviors of the agents of the labor market. By providing reviews on a regional level or by mentioning fraud in the context of the developing digital economy, there is only a common agreement that it should be expected that fraud levels will rise if no 
measures are taken though there is no common agreement on how they should be implemented.

\section{Conclusion}

This review highlighted the vulnerable state of the Russian labor market. This vulnerability is caused by the unstable economy which as an effect brings unemployment rates higher and contributes to the practice of deviant behaviors. The development of shadow markets, the complexity of the law, and lack of awareness from the side of workers combined with the effects of digitalization and challenges posed by the aftermath of the coronavirus crisis may bring in the future even more instability. Adaptation to the new realities, the inclusion of emerging employment types in institutions, and building trustful relationships among the agents of the market are tasks that have to be first solved on a state level.

Despite the fact the subject of the review is understudied, there is a common agreement that if measures are not taken, fraud in the labor market may start affecting other sectors of the economy, as well as have negative social effects such as lack of social security. In the context of growing uncertainty, deviant behaviors are expected to only grow further meaning that fraud and other deviances have to be assessed, analyzed, and slowly eliminated by a complex strategy including educating the agents of the market and proposing a new legislative framework that can be adapted by employers.

\section{References}

1. I.G. Andreeva, Edu Law, 4, 387-394 (2020). https://doi.org/10.24411/2076-1503-2020-00247

2. Ya.I. Gilinskii, Soc Stud, 4, 72-78 (1991)

3. D.G. Tkachenko, Sports: Econ, Law, Manag, 3, 29-31 (2020)

4. D.V. Golovanova, O.M. Dudina, Creative Econ, 13(6), 1253-1268 (2019)

5. Statya 159 UK RF. Moshennichestvo (deistvuyushchaya redaktsiya) [Article 159 of the Criminal Code of the Russian Federation. Fraud (current edition)]. Accessed on: October 4, 2021. [Online]. Available: https://www.zakonrf.info/uk/159/

6. K. Greenfield, Yale LJ, 107, 715 (1997)

7. D. Moher, A. Liberati, J. Tetzlaff, D.G. Altman, Brit Med J, 339, b2535 (2009). https://doi.org/10.1136/bmj.b2535

8. A.S. Kupreeva, A.R. Gazizov, Fraud as a problem in the labor market, in World Science: Problems and Innovations. Proceedings of the 18th International Scientific and Practical Conference. In 2 Parts, 56-58 (2018)

9. A.N. Kiryukhina, E.A. Morozova, A.V. Mukhacheva, Manag Iss, 3(64), 125-137 (2020). https://doi.org/10.22394/2304-3369-2020-3-125-137

10. Kh.V. Arturovich, K.A. Hasanbievich, Gaps Rus Leg, 5, 121-125 (2019)

11. D.V. Golovanova, O.M. Dudina, Creat Econ, 13(6), 1253-1268 (2019)

12. R. Urinboyev, Uzbek Migrants' Everyday Encounters with Employers and Middlemen, in Migration and Hybrid Political Regimes: Navigating the Legal Landscape in Russia, 62-80. (University of California Press, Oakland, 2021)

13. M.Yu. Markitanov, Devel Safety, 1, 105-114 (2019) 
14. T.N. Zhuravskaya, "To the Far East": Internet, labor mobility and discrimination in the labor market, in Fourth Industrial Revolution: Realities and Modern Challenges. The Tenth Anniversary Sociological Reading of Saint Petersburg. Proceedings of the International Scientific Conference, 38-40 (2018)

15. A.K. Kartseva, Econ Vector, 3(18), 61-64 (2019) 